\title{
BIOTECNOLOGÍA: MERCADOS Y BIOÉTICA
}

\author{
Rafael Vicuña
}

La biotecnología (BT) puede ser definida como la aplicación de organismos o sus partes para la producción de bienes y servicios. En términos generales, puede sostenerse que los procesos biotecnológicos son más eficientes y amigables con el medio ambiente que aquellos basados en tecnologías tradicionales. En este artículo se ofrecen argumentos en apoyo de los siguientes enunciados: (1) debido a su simplicidad técnica y a la presencia de algunos nichos estratégicos de interés local, la BT constituye una atractiva opción para los países en desarrollo; (2) el conocimiento científico y no la ideología o el mito debe ser el criterio empleado en la adopción de nuevas aplicaciones que generen controversia, tales como la producción de biocombustibles o los cultivos agrícolas genéticamente modificados, y (3) el respeto a la dignidad humana debe constituirse en el principio rector del diseño de nuevas terapias basadas en la manipulación de embriones.

RAFAel Vicuña. Bioquímico (Universidad de Chile) y PhD en Biología Molecular (Albert Einstein College of Medicine, Nueva York). Decano de la Facultad de Ciencias Biológicas, Pontificia Universidad Católica de Chile. Miembro de número de la Academia Chilena de Ciencias y de la Academia Pontificia de Ciencias del Vaticano. Autor de 80 publicaciones ISI en el campo de la enzimología y la expresión de los ácidos nucleicos y de 40 publicaciones de interés científico general.

Estudios Públicos, 110 (otoño 2008). 


\section{El auge de la biotecnología moderna}

$\mathrm{E}$ l siglo 20 fue testigo de avances revolucionarios en el ámbito científico. Durante las décadas iniciales, las ciencias físicas experimentaron una reformulación conceptual con la teoría de la relatividad de Einstein y la mecánica cuántica de Max Plank. Al promediar el siglo llegaría el turno de la biología, cuando Watson y Crick descifraron la estructura del ADN. Algo más tarde, durante los años setenta, la biología recibió otro impulso decisivo con el desarrollo de la biotecnología (BT) moderna, que fue posible gracias a los descubrimientos en el campo de la biología molecular.

Puesto que los científicos, al igual que los empresarios y los encargados de formular políticas públicas, suelen asignar distintos significados a la BT, para los efectos de esta presentación ella será definida como el uso de organismos vivos, o de sus componentes, para producir bienes y servicios. Esta amplia definición nos da a entender que la BT ha sido empleada durante varios siglos. Los fermentos utilizados por la industria de alimentos y bebidas, como asimismo producción microbiana de antibióticos por las empresas farmacéuticas, constituyen ejemplos típicos de BT tradicional. En cambio, la BT moderna puede involucrar la transferencia de genes entre especies en el laboratorio, técnica denominada ingeniería genética. Los genes pueden manifestarse en el organismo receptor, por cuanto el código genético es universal. La BT moderna también puede abarcar la manipulación de embriones y células, o el empleo de software avanzado para progresar aún más en el campo de la genómica, la proteómica y la metabolómica.

El ejemplo clásico de ingeniería genética es la producción de insulina. Antes del advenimiento de la BT moderna, a los diabéticos se les administraba una hormona aislada de bovinos u ovinos. En la actualidad, estos pacientes reciben una insulina humana modificada genéticamente y producida por microorganismos, que es más barata y más pura que la insulina aislada de animales. El mercado mundial para esta así llamada insulina recombinante asciende a una cifra cercana a los US\$ 3.000 millones anuales. Otra interesante aplicación de la ingeniería genética es la producción de vacunas. Tradicionalmente, las vacunas contra infecciones virales consistían en preparaciones virales que habían sido inactivadas mediante algún procedimiento que dañara su material genético. En ciertas ocasiones, cuando la inactivación viral no había sido del todo eficaz, estas vacunas inducían la aparición de la propia enfermedad que supuestamente debían prevenir. Dado que la respuesta inmunitaria es provocada por las proteínas asociadas al genoma viral, los genes que codifican dichas proteínas pueden ser clonados en diversas células para su producción en grandes cantidades. 
Varias vacunas que hoy están disponibles en el mercado consisten en proteínas recombinantes obtenidas por medio de la energía genética, las cuales, fuera de reducir los costos de producción, son más seguras que los virus inactivados. Un ejemplo típico de lo anterior es la vacuna contra la hepatitis, cuyo mercado mundial se calcula en US\$ 1.400 millones anuales.

La transferencia génica horizontal también ha sido aplicada al reino vegetal. Pese a tratarse de un tema sumamente polémico (véase más adelante), el área de los cultivos genéticamente modificados exhibe a nivel mundial un crecimiento sostenido que bordea el 10\% anual. Los principales cultivos transgénicos son la soja (57\%), el maíz (25\%), el algodón (13\%) y la canola (5\%). Otros cultivos transgénicos de importancia son el arroz, la calabaza, la papaya y la alfalfa. Las propiedades que de preferencia se transfieren a estos cultivos son la tolerancia a los herbicidas (68\%) y la resistencia a los insectos $(19 \%)^{1}$.

La transferencia génica a ovocitos recientemente fertilizados in vitro permite realizar la transgénesis en animales. Hasta ahora, la principal aplicación que se prevé en esta área es la producción de proteínas humanas con valor terapéutico. La modificación genética ha sido concebida de tal manera que el animal transgénico genere grandes cantidades de una valiosa proteína en uno de sus fluidos, comúnmente la leche. El único producto autorizado por el momento es la antitrombina III humana proveniente de cabras, aunque la alfaantitripsina y la lactoferrina derivadas de ovejas y conejos se encuentran en una avanzada etapa de prueba.

Como se mencionó anteriormente, la manipulación celular fue otra técnica fundamental que impulsó la BT. El cultivo in vitro de tejidos vegetales permite clonar plantas que revisten interés para las industrias agrícola, forestal y hortícola. En el caso de las células animales, la fusión de un linfocito con una célula cancerosa da origen a un hibridoma, una célula inmortal que produce anticuerpos (monoclonales) altamente específicos, de uso generalizado en la industria farmacéutica y en la investigación básica. La producción de células madre o troncales a partir de embriones de mamífero en una fase temprana de desarrollo (blastocistos) constituye otro ejemplo paradigmático de manipulación celular. Mantenidas en cultivo, estas células son capaces de crecer ilimitadamente y tienen la capacidad de diferenciarse para llegar a formar prácticamente cualquier tejido del cuerpo. Por tanto, se piensa que pueden constituir una fuente de tejido regenerativo para órganos en deterioro. La fragmentación de embriones humanos para obtener células madre pluripotentes tiene profundas connotaciones éticas, las que serán analizadas más adelante en este artículo.

\footnotetext{
${ }^{1}$ Datos obtenidos de www.isaaa.org.
} 
Una de las características distintivas de la BT moderna es el corto tiempo que transcurre entre un descubrimiento científico y sus aplicaciones prácticas. Actualmente existen 4.300 empresas cuyos procesos de producción se basan en la manipulación genética o celular utilizando animales, plantas o microorganismos. De ellas, cerca de 1.900 se encuentran en Norteamérica, 1.600 en Europa, y 750 en Asia. También es posible hallar algunas firmas exitosas en Latinoamérica, particularmente en Brasil, Argentina y Chile. Los ingresos declarados por estas empresas en 2006 ascendieron a US\$ 73.500 millones, mientras que sus gastos en investigación y desarrollo bordearon los US\$28.000 millones ${ }^{2}$. Las acciones de cerca del 10\% de estas modernas empresas basadas en la BT —entre las cuales no se cuentan ni las compañías farmacéuticas, ni los fabricantes de equipos médicos, ni las organizaciones de investigación por contrato — se transan públicamente en la bolsa de valores. Sin embargo, el negocio no ha sido fácil para estas compañías, como ha quedado demostrado por las frecuentes asociaciones y negociaciones de fusión y adquisición que tienen lugar en este sector.

A pesar de las notables innovaciones introducidas por la BT moderna, no hay que subestimar las ventajas de la BT tradicional. Procesos tales como la elaboración de bebidas alcohólicas y de fermentos lácteos, la descomposición anaeróbica de los desechos, el tratamiento biológico de aguas residuales domésticas e industriales, la reparación biológica de suelos, la producción de antibióticos, etc., siguen cumpliendo una importante función en la industria biotecnológica aun cuando, en su mayoría, utilicen microorganismos que no han sido sometidos a manipulación genética.

La BT tradicional también está prosperando en el campo de las enzimas. Estas proteínas catalíticas tienen numerosas aplicaciones en el sector industrial (alimentos y bebidas, detergentes, alimentos para animales, diagnóstico, medicina legal, bioetanol, celulosa, cuero, textiles, etc.), lo mismo que en la investigación. Se espera que el actual mercado mundial, que se sitúa en un nivel ligeramente superior a los US\$ 4.000 millones, aumente de manera progresiva hasta alcanzar una cifra cercana a los US\$ 5.000 millones para el año $2009^{3}$. Puesto que una de las características del producto es su alto valor agregado, el grueso de la demanda se ha concentrado tradicionalmente en manos de las naciones desarrolladas. Con todo, en una época más reciente países como China, Taiwán e India han surgido como centros mundiales de elaboración, favoreciendo de esta manera la tendencia del mercado al alza.

\footnotetext{
2 Lawrence, S.: “State of the Biotech Sector-2006”, 2007, p. 706.

3 http://www.the-infoshop.com/study/fd31270-enzymes.html.
} 


\section{La BT es una opción atractiva para las naciones en desarrollo}

Algunos podrían pensar que la BT, tradicional o moderna, requiere contar con personal altamente especializado y cuantiosas inversiones, y que por ende sólo resultaría adecuada para naciones industrializadas. De hecho, la gran mayoría de las empresas basadas en la BT moderna, lo mismo que las grandes firmas farmacéuticas y fabricantes de alimentos, tienen sus sedes en dichos países. No obstante, la BT ofrece una oportunidad inmejorable para generar riqueza y progreso social en las naciones en desarrollo. Esta aseveración se basa en dos argumentos. En primer lugar, las tecnologías que intervienen en la manipulación celular y genética no son en realidad demasiado complejas y suponen bajos costos. En consecuencia, pueden ser adoptadas fácilmente por las instituciones de investigación y por las industrias de la mayoría de los países del mundo. En segundo lugar, es posible encontrar nichos estratégicos que revisten un interés localizado. Como experiencias en este sentido se pueden mencionar el liderazgo mundial de Brasil en la producción de bioetanol, los esfuerzos de los sectores académico e industrial de Sudáfrica para combatir el SIDA; la creación de una vacuna contra el síndrome respiratorio agudo severo (SRAS) en China; y la producción de la primera vacuna contra la meningitis B por investigadores cubanos.

Chile también puede exhibir algunas iniciativas en este campo. Un interesante ejemplo es la producción de vacunas para los salmones. Nuestro país es el segundo productor en el mundo de salmones de criadero, con exportaciones cercanas a los US\$ 1.700 millones anuales (alrededor del 3\% de las exportaciones chilenas). Se estima que la actual producción anual de 600.000 toneladas se duplicará durante los próximos 5 años. Con todo, cada año los criadores de salmones están perdiendo alrededor de US\$ 200 millones debido a una enfermedad mortal llamada septicemia rickettsial salmonídea (SRS), que es causada por la bacteria Piscirickettsia salmonis. Puesto que este microorganismo provoca una infección intracelular en el pez, las vacunas tradicionales, basadas en la atenuación o en la eliminación de la bacteria, no superan el 30\% de eficacia. Un grupo de socios de empresas y fundaciones privadas decidió consagrar sus esfuerzos al desarrollo de una vacuna con un alto grado de eficacia (por lo menos 70\%), que al mismo tiempo fuera de bajo costo. Dado que en general el precio de venta por salmón es inferior a US\$10, se determinó que cada tratamiento no debía costar más de US\$ 0,10. Los socios que participaron en este proyecto fueron la fundación privada Ciencia para la Vida, la empresa BiosChile, la firma canadiense Acqua Health Ltd., además de Novartis Animal Health y Funda- 
ción Chile, esta última una joint venture entre el Gobierno chileno, ITT Corporation y BHP Billiton.

El proceso de creación de la vacuna contra la SRS constó de varias etapas. Primero se secuenció el genoma de $P$. salmonis y, mediante genómica comparativa con otras bacterias, se escogieron 16 genes para la producción de antígenos. Estos fueron creados por medio de la tecnología del ADN recombinante en la bacteria Escherichia coli, y posteriormente fueron sometidos a prueba en diversas combinaciones en peces infectados con $P$. salmonis. Con un extracto crudo que contenía una mezcla de tres antígenos se obtuvo una respuesta inmunitaria con un 90\% de eficacia. La producción en gran escala de la vacuna se inició formalmente en 2006 en las instalaciones industriales de Novartis en Nueva Inglaterra (EE.UU.) y en Canadá, y ya se estaba comercializando a fines de ese año. Debido a que la $P$. salmonis sólo prolifera en el Hemisferio Sur, hasta la fecha el mercado para esta vacuna se ha localizado principalmente en Chile. De todos modos, los piscicultores del Hemisferio Norte no descartan la posibilidad de que la bacteria aparezca en esa región, por lo que constantemente están inspeccionando su eventual presencia mediante un equipo de verificación creado por BiosChile. Por otra parte, Novartis ha decidido aumentar el valor agregado de este producto incluyendo antígenos para otras enfermedades que afectan a los peces. Así pues, además de la vacuna contra la SRS ya descrita, también se están elaborando dos vacunas multivalentes: una que inmuniza contra la SRS, el virus de la necrosis pancreática infecciosa y el Vibrio ordalii; y otra que inmuniza contra la SRS y la Aeromonas. El proyecto en su conjunto, incluidas la investigación inicial, las fases de desarrollo y la producción en gran escala, requirió cerca de 7 años, con un costo aproximado de US\$ 5 millones. Se espera que, en un escenario donde hoy en día no existe ninguna vacuna eficaz, el mercado para este producto alcance los US\$ 30 millones, permitiendo así que la industria salmonera chilena ahorre US\$ 130 millones.

El caso anterior ilustra claramente cómo gracias a la colaboración y la formación de alianzas adecuadas se puede llegar a encontrar una solución innovadora en un país con un bagaje tecnológico relativamente limitado. Ninguno de los actores individuales en este proyecto contaba con las aptitudes y los conocimientos necesarios para resolver el problema por sí solo. Pero gracias a las competencias de BiosChile en materia de genómica, a la experiencia científica de la Fundación Ciencia para la Vida, a los conocimientos técnicos y las instalaciones para ensayos con peces de Fundación Chile, y a las capacidades de producción y comercialización de Novartis, estos socios produjeron y comercializaron una vacuna eficaz. Motivadas por el 
éxito alcanzado y la experiencia adquirida en este proyecto, ahora dichas entidades han aunado esfuerzos para realizar investigaciones sobre la bacteria Streptococus focae, que también afecta a la población salmonícola chilena.

Otra interesante iniciativa emprendida en Chile es la biolixiviación del cobre, aplicación que está siendo optimizada a través de investigaciones científicas para obtener una mayor rentabilidad. En la actualidad las compañías mineras obtienen este metal mediante la pirometalurgia o la hidrometalurgia. El primer proceso, empleado principalmente con minerales enriquecidos en sulfuros de cobre, consiste en el chancado y cribado del mineral metálico, la flotación de partículas finas de sulfuros, la fundición para formar cobre blíster (97\% a 99\%), y el refinado por electrólisis o calor. Por su parte, la hidrometalurgia está destinada a los minerales enriquecidos en óxidos de cobre. En este caso, el mineral chancado se deposita en una pila que cuenta con una serie de mangueras que distribuyen ácido sulfúrico diluido. La solución lixiviada que contiene cobre disuelto es sometida a un proceso de extracción por solventes con una sustancia química que se adhiere al metal y lo extrae de manera selectiva. Más adelante, a esta sustancia se le extrae el contenido de cobre para poder reutilizarla; la suspensión de concentrado de cobre se disuelve en ácido sulfúrico y se envía a celdas electrolíticas para recuperar los cátodos de cobre. En cualquiera de estos procesos se pierde un importante porcentaje del cobre presente originalmente en el mineral. Por lo tanto, un procedimiento que permitiera recuperar este cobre residual, o extraer el cobre de los minerales de baja ley que no han sido explotados por motivos económicos, sería muy valioso para la industria minera.

La BT ofrece una solución a este problema. Existen bacterias que obtienen la energía necesaria para su reproducción y crecimiento al oxidar los sulfuros de cobre. Dichas bacterias habitan normalmente en las minas de cobre, y cuando están presentes en los botaderos o pilas irrigados la lixiviación del cobre con ácido diluido se torna más eficiente. Pese a que la biolixiviación de minerales ricos en sulfuros requiere más tiempo que la lixiviación química de los óxidos de cobre, ello no debería representar un inconveniente cuando la alternativa consiste en desperdiciar el cobre presente en los minerales de baja ley o en el material ya procesado. La investigación en el área de la biolixiviación está permitiendo obtener microorganismos más eficientes, cuyas propiedades fisiológicas son objeto de estudio. Los aspectos relativos a la ingeniería también están siendo investigados, de manera de garantizar un masivo crecimiento bacteriano y una homogénea irrigación de ácido. 
Chile es uno de líderes mundiales en esta reciente aplicación de la BT. El cobre representa el 45\% de las exportaciones chilenas, con una producción total de alrededor de 5,5 millones de toneladas anuales (la demanda mundial es de 18 millones de toneladas). Cerca del 33\% de ellas son producidas por hidrometalurgia, y la tercera parte de ese porcentaje corresponde a bio-hidrometalurgia. En 2002 la empresa estatal CODELCO Chile, la mayor productora mundial de cobre, en conjunto con Nippon Mining \& Metals Co. Ltd., crearon BioSigma. La misión de esta nueva joint venture pública y privada, que también recibió apoyo del Programa Genoma Chile, consiste en formular una BT sustentable a fin de explotar recursos minerales de baja ley y otros materiales secundarios mediante la extracción in situ, es decir sin necesidad de recurrir a la pirometalurgia. La empresa ha identificado y patentado tres nuevas cepas de bacterias y ha secuenciado sus correspondientes genomas. El año pasado, estas bacterias fueron inoculadas en una pila de 50.000 toneladas para producir el primer cátodo de cobre que utiliza tecnología desarrollada por BioSigma. Pese a que aún es demasiado temprano para determinar si BioSigma logrará el objetivo de reemplazar la pirometalurgia por un proceso que ofrezca una mejor relación costo-eficacia, esta iniciativa puede llegar a transformarse en otro ejemplo revolucionario de biotecnología exitosa desarrollada en un país no industrializado.

\section{El conocimiento fundamentado, en lugar de la ideología o los mitos, debe ser el criterio que inspire la adopción de nuevas tecnologías}

Dos aplicaciones de la BT, cuyo impacto en las naciones en desarrollo es al parecer muy significativo, están suscitando una viva controversia en todo el mundo. Se trata de la producción de biocombustibles y de cultivos transgénicos. Estos ejemplos resultan particularmente apropiados para ilustrar el hecho de que cuando existe incertidumbre respecto de los beneficios sociales de una determinada innovación, la toma de decisiones debe basarse en el conocimiento científico y no en la ideología o los mitos. Desgraciadamente, son estos últimos criterios los que han predominado en el debate en torno a aquellos dos temas tan trascendentales.

Analicemos en primer lugar el caso de los biocombustibles. La creciente demanda de energía para calefacción, transporte y actividades industriales está provocando un sostenido aumento del consumo de petróleo. A nivel mundial, los países se están esforzando por diversificar sus fuentes de energía, no sólo para hacer frente al inestable precio del petróleo, sino también para reducir las emisiones de gases de combustibles fósiles que produ- 
cen el efecto invernadero. Sólo por mencionar un ejemplo, en 2005 EE.UU. consumió 140.000 millones de galones de gasolina plus diésel sólo para fines de transporte, y los vehículos que quemaron ese combustible expulsaron a la atmósfera más de 308 millones de toneladas métricas de carbono ${ }^{4}$.

Muchos estiman que el uso de biocombustibles contribuirá enormemente a mitigar ambos problemas. Pueden mezclarse en una proporción de hasta $10 \%$ con gasolina sin dañar los motores convencionales. En algunos lugares existe también la alternativa de una mezcla E85, que consiste en 85\% de bioetanol y 15\% de gasolina sin plomo, aunque con esta fórmula es preciso adaptar los motores. Por otra parte, la combustión del bioetanol o del biodiésel utiliza carbono que está siendo reciclado por la fotosíntesis. Por tanto, los biocombustibles parecen representar una opción atractiva, aunque la situación puede variar considerablemente de un país a otro.

La generación de energía por medio de la BT convencional está cobrando impulso. En 2006, EE.UU. elaboró 4.500 millones de galones de bioetanol a partir de granos de maíz, y se espera que para fines de 2008 la capacidad de producción alcance los 13.000 millones de galones. El proceso comprende una etapa de licuefacción para solubilizar el almidón, un tratamiento enzimático para descomponer este polímero, seguido de la fermentación de la levadura de los azúcares resultantes ${ }^{5}$. Es probable que esta tendencia se mantenga gracias a una serie de incentivos tributarios y a una legislación adecuada. En diciembre de 2007, el presidente Bush sancionó una nueva ley de energía que dispone la producción de 36.000 millones de galones de combustible renovable para el año 2022, con lo cual prácticamente se quintuplica el objetivo establecido en la Ley de Política Energética promulgada en 2005. La nueva normativa estipula que 15.000 millones de galones deben provenir del etanol de maíz, y que el resto debe derivar de fuentes tales como residuos agrícolas lignocelulósicos, Panicum virgatum (switchgrass) y biodiésel.

Sin embargo, teniendo en cuenta el actual proceso de producción, es preciso superar algunas dificultades a fin de permitir que los biocombustibles cumplan con las expectativas que se han cifrado en ellos. El etanol contiene dos tercios de las btu (British Termal Units) presentes en el mismo volumen de gasolina. En consecuencia, aun cuando el costo de convertir materia vegetal en un galón de etanol es inferior al precio de un galón de gasolina, los conductores tendrían que bombear más etanol para recorrer la misma distancia. Otro inconveniente es que para destilar el alcohol tras el

${ }^{4}$ Nature Biotechnology, 24, 2006, Editorial, p. 725.

${ }^{5}$ Angenent, L. T.: "Energy Biotechnology: Beyond the General Lignocelluloseto-Ethanol Pathway”, 2007, pp. 191-192. 
proceso de fermentación se requiere emplear gas natural. Con el actual proceso industrial, para elaborar un galón de bioetanol (80.000 btu de energía) se necesitan cerca de 36.000 btu de gas natural. El alto nivel de demanda ha elevado el precio del gas hasta niveles que resultan económicamente poco rentables, por lo que algunos productores en EE.UU. hoy están utilizando carbón, solución que no parece apropiada cuando el objetivo es reducir las emisiones que causan el efecto invernadero. Otras etapas en que se requiere energía para producir bioetanol son la síntesis química de los fertilizantes, la cosecha del maíz o de la caña de azúcar, y el transporte del bioetanol al mercado. Según una reciente estimación realizada por el American Institute of Biological Sciences, en EE.UU. la producción de etanol a partir del almidón de maíz sólo genera una cantidad de energía superior en $10 \%$ a la que se requiere para elaborarlo.

Otra área de debate se refiere a los beneficios del bioetanol cuando se trata de reducir el efecto invernadero. Algunos sostienen que el alto nivel de consumo de gas natural sólo le concede una ligera superioridad respecto de la gasolina, y que si el gas natural es reemplazado por carbón la ventaja es nula. A este dilema se suma el hecho de que el uso intensivo de fertilizantes nitrogenados en el cultivo del maíz se traduce en la emisión de considerables cantidades de óxido nitroso, gas que es un poderoso inductor del efecto invernadero. Por otra parte, algunos estudios han demostrado que el hecho de convertir las superficies forestales y los pastizales en nuevas tierras de cultivo para replantarlas con cereales cuyo empleo se ha desviado hacia la elaboración de biocombustibles provoca como efecto neto un aumento de las emisiones de gases causantes del efecto invernadero $^{6,7}$. Se observan, asimismo, desventajas relacionadas con el uso alternativo del maíz. Hoy en día el maíz se emplea como alimento para seres humanos y como pienso, y su desvío hacia la producción de bioetanol ha generado un alza en el precio de productos derivados del maíz, y como consecuencia de ello el costo de la carne también ha subido. Ahora bien, incluso si el total de la cosecha de maíz en los EE.UU. se destinara a la producción de bioetanol, sólo serviría para suministrar el 7\% del combustible consumido por sus vehículos. En este mismo sentido, un estudio reciente indica que para sustituir la gasolina en un $10 \%$ se requiere utilizar un $43 \%$ de las tierras de cultivo ${ }^{8}$. Estos obstáculos han llevado a la OCDE a declarar

\footnotetext{
${ }^{6}$ Searchinger, T., R. Heimlich, R. A. Houghton, F. Dong, A. Elobeid, J. Fabiosa, S. Tokgoz, D. Hayes y T-H. Yu: "Use of U.S. Croplands for Biofuels Increases Greenhouse Gases through Emissions from Land Use Change”, 2008, pp. 1238-1240.

${ }^{7}$ Fargione, J., J. Hill, D. Tilman, S. Polasky y P. Hawthorne: "Land Clearing and the Biofuel Carbon Debt”, 2008, pp. 1235-1237.

${ }^{8}$ Righelato, R. y D. V. Spracklen: "Carbon Mitigation by Biofuels or by Saving and Restoring Forests?”, 2007, p. 902.
} 
que los biocombustibles ofrecen un remedio que puede acabar siendo peor que la enfermedad.

Todos estos factores requieren la explotación de las lignocelulosas en lugar del almidón como fuente de azúcares fermentables. Las materias primas lignocelulósicas son notoriamente más abundantes que las materias primas agrícolas convencionales, y por tanto minimizan el conflicto en torno al uso de la tierra para producir energía en lugar de alimentos o pienso. Las lignocelulosas se encuentran en los tallos del maíz, la paja de los granos, la biomasa de algunos pastos de rápido crecimiento, y los residuos de la industria maderera. Por tanto, en la producción de las lignocelulosas se consume una cantidad mucho menor de pesticidas y fertilizantes que en los cultivos agrícolas tradicionales. Desgraciadamente, puesto que la solubilización de los azúcares fermentables a partir de las lignocelulosas es mucho más difícil que a partir del almidón, la producción de bioetanol derivado de ellas resulta hoy en día económicamente inviable. Es preciso realizar investigaciones para superar esta limitación. Los principales objetivos son la despolimerización de la celulosa y las hemicelulosas, la fermentación eficiente de la mezcla de azúcares, y un uso rentable de la lignina. En la industria de la pulpa papelera es bien sabido que la lignina tiene buena combustión, y en varias fábricas de pulpa se utiliza para generar electricidad. Las emisiones netas de dióxido de carbono por cada $1,5 \mathrm{~km}$ recorridos en un vehículo propulsado por etanol de celulosa disminuirían abruptamente si la electricidad derivada de la lignina pudiera desplazar al carbón o al gas natural como fuente de energía. Ya se han realizado progresos considerables con miras a integrar el proceso y reducir los costos de capital. Las cepas microbianas han sido modificadas metabólicamente para fermentar ambos tipos de azúcar. También se ha intentado integrar los procesos mediante la despolimerización y fermentación simultánea de los polisacáridos (proceso SSCF por su sigla en inglés: Simultaneous Saccharification and CoFermentation). En la actualidad, los científicos están sometiendo a ensayo el método del bioprocesamiento consolidado (consolidated biopsocessing, CBP), que consiste en la modificación de microorganismos que producirían las enzimas hidrolíticas y fermentarían todos los azúcares.

Si el etanol lignocelulósico va a ser lanzado al mercado alguna vez todavía es materia de debate. Dependerá del precio del petróleo, del éxito de las investigaciones y de otros factores, como la mentalidad y los objetivos de la industria automotora estadounidense. Aun así, este objetivo, que parece tan decisivo para EE.UU., tal vez no resulte tan fundamental para otros países. En 2006, Brasil produjo un volumen similar de bioetanol (4.500 millones de galones) mediante fermentación directa del azúcar de caña. El equili- 
brio energético de este proceso es mucho más favorable que el de aquel que utiliza almidón. El programa brasileño de producción de bioetanol fue puesto en marcha a raíz de la crisis del petróleo de 1973, y ha experimentado altibajos que han dependido del precio del crudo. En 2004 se vendieron los primeros automóviles con motor Flex. Estos vehículos funcionan con puro etanol, con pura gasolina, o con una mezcla de ambos. En 2006, el 73\% de todos los automóviles nuevos vendidos en Brasil contaban con motor Flex. El incentivo para usar el etanol estriba en su precio, que puede ser $40 \%$ inferior al de la gasolina debido a la disponibilidad de materia prima, a la relativa simplicidad del proceso, y al bajo costo de la mano de obra. Al parecer no existen obstáculos para que esta bioindustria estratégica brasileña continúe desarrollándose. Actualmente ese país se encuentra en plan de reducir sus importaciones de petróleo en 200.000 barriles diarios, con el beneficio adicional de que la producción de bioetanol genera empleo y se dispone de una enorme superficie cultivable para plantar la caña de azúcar.

El área de los biocombustibles incluye, asimismo, la producción de biodiésel, que consiste en una mezcla de ésteres orgánicos contenidos en aceites animales y vegetales. El biodiésel puede emplearse como sustituto del petróleo diésel, de la misma manera en que el bioetanol reemplaza a la gasolina. En este caso la principal materia prima es la semilla de colza. En la Unión Europea el bioetanol aún no se ha convertido en una opción atractiva, debido a la falta de tierras. Así y todo, en 2005 la producción de biodiésel ascendió a 3,2 millones de toneladas, lo que supuso un aumento del 65\% con respecto a 2004. Recientemente, la Comisión Europea ha lanzado un plan cuyo objetivo es que para el año 2020 los biocombustibles lleguen a representar un $10 \%$ de los carburantes usados en el transporte. Las políticas de exención tributaria aplicadas en Alemania, España, el Reino Unido, Italia y Francia, están orientadas en este sentido.

La producción de biodiésel es una iniciativa interesente puesto que no necesariamente compite con el cultivo de alimentos. El combustible puede ser elaborado a partir de algunas plantas específicas, como también a partir de algas e incluso de desechos. Un ejemplo de este último caso es el plan anunciado por McDonald's de convertir los motores de todos sus camiones repartidores en el Reino Unido para que funcionen con biodiésel producido a partir de sus enormes existencias de aceite de cocina usado. También puede mencionarse el prometedor caso de la planta conocida como jatrofa (Jathropa curcas) ${ }^{9}$, un espécimen silvestre que ha sido usado por años como materia prima para fabricar aceite de lámparas y jabón. Su rendimiento en litros de petróleo por hectárea (1.300) se compara favorablemente

\footnotetext{
${ }^{9}$ Fairless, D.: “The Little Shrub that Could-Maybe”, 2007, pp. 652-655.
} 
con el de la colza (1.100) y el de la soya (400). Esta planta se da bien en páramos no arables, y su cultivo puede detener la erosión, aumentar el porcentaje de almacenamiento de agua en el suelo y de este modo transformar terrenos infértiles en superficies productivas. En 2003, la Comisión de Planificación de la India recomendó plantar 500.000 hectáreas de jatrofa y, en caso de observarse algún progreso en el programa de biocombustibles, aumentar la superficie a 12 millones de hectáreas. El servicio de ferrocarriles ya ha distribuido un millón de plántulas a lo largo de sus vías para el consumo futuro. China también planea disponer de una extensión similar plantada con jatrofa para el 2010. Pese a todo, existe un importante motivo de preocupación: la planta nunca ha sido domesticada y poco se sabe acerca de su biología. El tiempo dirá si se cumplen las expectativas cifradas en este recurso.

Como ya se mencionó, otra aplicación de la BT que ha suscitado controversias a nivel mundial es la modificación genética de las plantas. Sin embargo, pese al debate actualmente en curso, en 2007 el valor en el mercado mundial de los cultivos modificados genéticamente (a los que en adelante denominaremos cultivos biotecnológicos) fue calculado en US\$ 6.900 millones, lo cual equivale al $20 \%$ del mercado mundial de semillas comerciales. Ese mismo año, la superficie mundial de cultivos biotecnológicos alcanzó los 114,3 millones de hectáreas ${ }^{10}$. Hoy en día 23 países cuentan con más de 50.000 hectáreas plantadas, mientras que otros 29 han autorizado su importación y consumo. La tolerancia a los herbicidas transferida a la soya, el maíz, la canola, el algodón y la alfalfa cubre el 72\% de las tierras destinadas a cultivos biotecnológicos a nivel mundial. Otro 19\% corresponde a un rasgo codificado naturalmente en un gen bacteriano que otorga resistencia a los insectos, en tanto que un 13\% de la tierra está plantada con cultivos en que se combinan rasgos para la tolerancia a los insectos y a los herbicidas. Aun cuando cerca del $60 \%$ de los cultivos transgénicos se concentra en EE.UU. y Canadá, las naciones en desarrollo también están adoptando esta tecnología. De ellas, Argentina, Brasil, China e India constituyen los casos más notables, pues albergan el 33\% de la superficie plantada total de cultivos biotecnológicos. Con todo, estudios recientes también han demostrado que la rentabilidad difiere de un país a otro, o incluso entre las distintas regiones de un mismo país ${ }^{11}$. Esta variación obedece a factores institucionales tales como las legislaciones locales (o la ausencia de ellas), las normas ambientales y los derechos comerciales y de propiedad intelectual.

\footnotetext{
${ }^{10}$ La mayoría de estos datos fueron obtenidos de www.isaaa.org.

${ }^{11}$ Raney, T.: "Economic Impact of Transgenic Crops in Developing Countries”, 2006, pp. 174-178.
} 
La situación paradójica de Chile a este respecto indica la necesidad de contar con un marco legal adecuado. Los agricultores chilenos pueden plantar cultivos genéticamente modificados para exportación de semillas, e importar alimentos y pienso biotecnológicos, pero no pueden plantar cultivos biotecnológicos para consumo local.

La Unión Europea se ha caracterizado por una tradicional falta de entusiasmo respecto de los cultivos biotecnológicos. Hace algunos años, EE.UU. se quejó ante la Organización Mundial de Comercio, alegando que la renuencia europea a aceptarlos obedecía a una mera actitud proteccionista, la cual últimamente parece estar perdiendo terreno en forma gradual, aunque sólo en el caso de las plantaciones en pequeña escala. Hoy en día, en 6 de los 25 países miembros de la UE existen plantaciones de una variedad de maíz resistente a los insectos, el único cultivo biotecnológico aprobado hasta ahora. Entre las especies que se encuentran en lista de espera para su autorización pueden mencionarse dos variedades de maíz que han sido modificadas para resistir pestes y herbicidas, pero aún está pendiente su visto bueno por parte del Comisionado de la UE para el Medio Ambiente.

Una de las características más interesantes de los cultivos biotecnológicos es que más de 10 millones de agricultores están dedicados a esta actividad, alrededor del 90\% de ellos en China, India y Filipinas. El rápido aumento de esta cifra es un reflejo de que se están obteniendo beneficios tales como un menor consumo de pesticidas, una reducción en los costos de producción y un mejor rendimiento de las cosechas. Lo anterior contradice el argumento de que estos productos sólo benefician a los agricultores capaces de aprovechar las ventajas de las economías en gran escala ${ }^{12}$. Una encuesta reciente ${ }^{13}$ permite apreciar que la utilidad total obtenida por los agricultores biotecnológicos durante la última década ascendió a US\$ 27.000 millones, suma que se distribuye equitativamente entre países en desarrollo e industrializados. La disminución en el uso de pesticidas a lo largo de ese mismo período fue de 224.000 toneladas, con el consiguiente beneficio ambiental derivado de un menor consumo de combustibles fósiles en su producción. Parece razonable prever que la mejoría en el rendimiento de las cosechas permitirá liberar una mayor superficie de tierra para sembrar plantas dedicadas a la producción de biocombustibles, lo cual reportará beneficios ambientales adicionales.

Otro desafío fundamental con miras a favorecer a los agricultores biotecnológicos de países en desarrollo consiste en aumentar la capacidad

\footnotetext{
12 Raney, T. y P. Pingali: “Sowing a Gene Revolution”, 2007, pp. 104-111.

13 Brookes, G. y P. Barfoot: "GM Crops: The First Ten Years. Global SocioEconomic and Environmental Impacts”, 2006.
} 
de investigación de estas naciones. La anterior revolución verde, que permitió elevar la productividad agrícola empleando métodos convencionales de cultivo por selección genética, fue encabezada por investigadores de instituciones académicas y del sector público. En contraste, la nueva revolución genética está impulsada en importante medida por empresas multinacionales que patentan sus descubrimientos. Se trata de un aspecto clave, por cuanto el interés de las firmas privadas estriba principalmente en la existencia de productos de alta rentabilidad. En algunos casos, el mayor costo de las semillas modificadas genéticamente puede compensarse con un menor consumo de pesticidas, con un mayor rendimiento, o con ambas ventajas. Así y todo, es probable que estos productos no satisfagan las necesidades de algunas regiones menos desarrolladas del planeta. Por ejemplo, en ciertos países tal vez sea preciso aumentar el valor nutricional de cultivos que son importantes para su dieta, o mejorar el bajo rendimiento derivado de la mala calidad de los suelos. En la actualidad, China desarrolla sus propios cultivos biotecnológicos, mientras que Brasil, India y Sudáfrica están progresando en esta área, si bien todavía no producen cultivos comerciales.

Existe un elemento adicional que explica el éxito de esta moderna revolución agrícola que se ha extendido por todo el planeta: la percepción pública. Se trata de un aspecto de suma importancia para esta aplicación de la BT, ya que hemos sido testigos de situaciones de extrema intolerancia, como la destrucción de cultivos biotecnológicos y violentas agresiones contra restaurantes de comida rápida que utilizan ingredientes modificados genéticamente. Las discrepancias en torno al tema no deberían causar sorpresa, ya que es sabido por todos que la gente se muestra reacia a los cambios. Cuando los españoles trajeron la papa a Europa en 1570, nadie estaba dispuesto a comerla. Sin duda producto de una mezcla de superstición y mito, en un principio se creyó que era tóxica y después que causaba lepra. Paradójicamente, la tortilla de papa es hoy uno de los platos más típicos de España. Con mucha frecuencia escuchamos a políticos, a periodistas, a ambientalistas y al público en general debatir acerca de los cultivos modificados genéticamente, con argumentos que las más de las veces carecen de base científica y están cargados de subjetividad. Algunos sostienen que la introducción de genes (y promotores) foráneos podría activar virus que se encuentran en estado latente en las plantas. Otros argumentan que los alimentos biotecnológicos son tóxicos, causan alergias o aumentan la resistencia de los consumidores a los antibióticos. Algunos llegan incluso a aseverar que los cultivos biotecnológicos promoverán el flujo de genes hacia cultivos relacionados o plantas silvestres, que generarán un aumento en el uso de pesticidas y herbicidas, que afectarán la biodiversidad, etc. 
Pese a que a priori estas imputaciones podrían tener algún fundamento racional, ninguna de ellas ha sido demostrada científicamente. Las denuncias relativas a las alergias o a la toxicidad resultan especialmente improcedentes cuando el producto comestible derivado de un cultivo biotecnológico no puede distinguirse del convencional, como es el caso del azúcar o del aceite.

Por cierto que es razonable tomar precauciones antes de autorizar la plantación y comercialización en gran escala de un nuevo cultivo biotecnológico, pero ello debe hacerse dentro del marco de legislaciones y normativas que no sean obstruccionistas. Por ejemplo, si existe preocupación acerca de posibles repercusiones en la salud humana o en el medio ambiente, deberán realizarse pruebas que se ajusten a los protocolos reglamentarios. Posteriormente podrá adoptarse una decisión basada en evidencias científicas y no en prejuicios, emociones o mitos. A este respecto, las declaraciones públicas emitidas por las academias de ciencias de EE.UU., Brasil, China, India, México, Reino Unido, Chile, el Vaticano, como también por la Academia de Ciencias para el Mundo en Desarrollo (Third World Academy of Sciences, TWAS), podrían servir como un adecuado criterio de orientación.

El caso del arroz es el más apropiado para ilustrar con mayor claridad la importancia de la percepción pública. Como es bien sabido, este cultivo constituye un componente esencial de la dieta de varios países en desarrollo. Hace dos años, Irán fue el primer país en aprobar la producción comercial de una variedad de arroz transgénico para consumo humano resistente a las pestes. Hasta la fecha, China se ha mostrado reacia a hacer lo propio, por temor a una reacción negativa de parte de los países importadores de arroz chino. Puede mencionarse, asimismo, el caso del arroz dorado (golden rice), enriquecido con betacaroteno para compensar el déficit de vitamina $\mathrm{A}$ en poblaciones que sufren desnutrición. La vitamina A cumple una función esencial en diversos procesos fisiológicos, como la visión, el crecimiento, el desarrollo normal y la inmunidad a las enfermedades. Cada año, medio millón de personas, en su mayoría niños, quedan ciegas como consecuencia de una deficiencia de vitamina A, y de ellas la mitad pueden fallecer un año después de perder la vista ${ }^{14}$. Desarrollado originalmente en Europa el año 2001 con genes provenientes de plantas y bacterias, el arroz dorado fue perfeccionado más tarde con un gen derivado del maíz, lo cual permitió aumentar en 20 veces el contenido de precursores de la vitamina A. Un estudio reciente ${ }^{15}$ ha revelado que $100 \mathrm{~g}$ de arroz dorado proporcionan la

\footnotetext{
${ }^{14}$ Mayer, J. E.: “Golden Rice, Golden Crops, Golden Prospects”, 2007, pp. 22-34.

15 "Nutritional and Safety Assessments of Foods and Feeds Nutritionally Improved through BT: Case Studies”, 2007, 00579.x.
} 
dosis diaria recomendada de vitamina A para un niño en edad preescolar. Por otra parte, en un informe del Banco Mundial se sostiene que el aumento en los niveles de bienestar que podrían experimentar los países que adoptaran el arroz dorado sería del orden de miles de millones de dólares anuales $^{16}$. La llamada Red Humanitaria del Arroz Dorado, encabezada por Ingo Potrykus, ha puesto este arroz a libre disposición de centros de investigación que se encuentran desarrollando variedades adaptadas localmente en numerosos países. Sin embargo, en ninguno de ellos se ha autorizado aún el cultivo del arroz dorado para consumo humano. Algunos carecen de una legislación apropiada o de procedimientos de seguridad biotecnológica, en tanto que otros todavía no han puesto a prueba su seguridad para el medio ambiente y la salud humana. Se espera que las variedades locales de arroz dorado sean lanzadas al mercado dentro de un par de años. En el otro rincón del cuadrilátero se encuentran los enemigos de esta planta, que la han criticado desde un comienzo. Sus detractores afirman que se han sobreestimado los posibles beneficios de este cultivo, mientras que otros aseveran que existen alternativas más económicas para combatir la deficiencia de vitamina A. El debate aún persiste, e independientemente de cuál sea su desenlace nadie podrá negar que consumir un arroz dorado que haya superado todas las barreras de seguridad será más beneficioso para la salud humana que ingerir el arroz tradicional, especialmente en los países más pobres.

\section{Biotecnología y bioética}

Tanto la manipulación genética como la celular de organismos vivos tienen implicaciones de carácter bioético. Cuando se practican en microorganismos, plantas y animales, es preciso atenerse a las correspondientes directrices de seguridad. Ellas consisten en protocolos reglamentarios que han sido concebidos para prevenir daños a la salud humana, salvaguardar el bienestar de animales genéticamente modificados y proteger el medio ambiente. Con todo, las preocupaciones bioéticas resultan particularmente pertinentes cuando se refieren a la manipulación de células y genes humanos. Y si bien este tema no tiene que ver con las aplicaciones bioéticas descritas anteriormente, no cabe adoptar una actitud de indiferencia moral, atendida su profunda trascendencia social.

En los últimos años hemos presenciado una agria controversia en torno a la utilización de células madre embrionarias para aliviar diversas

${ }^{16}$ Anderson, K., L. A. Jackson, C. Pohl Nielsen: “Genetically Modified Rice Adoption: Implications for Welfare and Poverty Alleviation”, 2004. 
enfermedades. Si bien tal vez se trate de un método terapéutico prometedor que permita dar esperanzas a millones de pacientes de todo el mundo, supone la destrucción de embriones humanos para obtener las células. Estos embriones pueden corresponder a restos de procesos de fertilización in vitro, o pueden ser creados con el solo fin de obtener células madre. Esto último añade otras complicaciones, como el hecho de determinar quién suministrará los óvulos, cómo se pagará a los donantes y cuáles serán sus derechos, en caso de que los tengan. Incluso peor resulta la posibilidad de producir embriones humanos mediante el transplante nuclear, eufemismo que suele emplearse para evitar mencionar la palabra clonación. Cualquiera sea la circunstancia, el embrión merece ser tratado con el debido respeto, ya que corresponde a una vida humana en sus etapas de desarrollo más tempranas. ¿Cómo es posible que un tratamiento que se precia de salvar una vida humana esté basado en la destrucción de la misma en su estado embrionario? Esta perspectiva utilitaria, que da a entender que el fin justifica los medios, resulta lógica y moralmente contradictoria, como lo es cualquier producción de embriones humanos con el fin, directo o indirecto, de experimentar con ellos o eventualmente destruirlos ${ }^{17}$. No es un asunto que le concierna a una religión en particular. Simplemente es una intuición innata la que nos dice que hay algo especial en el hecho de ser humanos. Podemos reconocer que esta diferencia fundamental está vinculada a nuestra racionalidad, que constituye la base de la dignidad humana. Esta dignidad se manifiesta en una conciencia ética, en la capacidad de amar, de comprender y de crear. También se hace patente en la capacidad de transmitir valores culturales, en el derecho a la libertad, a la autonomía y a la intimidad. Como lo expresó Kant, cada persona es un fin en sí misma. Por fortuna existen alternativas al uso de células madre embrionarias. Hay células troncales provenientes de tejidos adultos, o de tejidos superfluos para el desarrollo normal del feto. Aun cuando estas células madre parecen exhibir menos plasticidad que las células embrionarias, estudios clínicos ya publicados revelan que las células madre adultas han sido usadas para tratar más de 60 enfermedades en pacientes humanos. Por otra parte, dos grupos han demostrado recientemente que es posible reprogramar células de piel humana para obtener células pluripotentes ${ }^{18,19}$. Por consiguiente, es menester incentivar a los

${ }^{17}$ Discursos de Juan Pablo II a los miembros de la Academia Pontificia de Ciencias, 10 de noviembre de 2003.

${ }^{18}$ Takahashi, K., K. Tanabe, M. Ohniki, M. Narita, T. Ichisaka, K. Tomoda y S. Yamanaka: "Induction of Pluripotent Stem Cells from Adult Human Fibroblasts by Defined Factors”, 2007, pp. 861-872.

${ }^{19}$ Yu, J., M. A. Vodyanik, K. Smuga-Otto, J. Antosiewicz-Bourget, J. L. Frane, S. Tian, J. Nie, G. A. Jonsdottir, V. Ruotti, R. Stewart, II. Slukvin, J. A. Thomson: "Induced Pluripotent Stem Cell Lines Derived from Human Somatic Cells”, 2007, pp. 1917-1920. 
científicos para que concentren sus futuras investigaciones en el uso de células madre no embrionarias, las cuales ya han demostrado ser terapéuticamente beneficiosas.

Similares motivos asociados a la dignidad humana permiten esgrimir un argumento de peso contra la práctica de la manipulación de genes humanos. En primer lugar, la decisión relativa a un cambio irreversible en el genotipo que sería transmitido a generaciones futuras la adoptarían personas que no se verían afectadas por dicha alteración. Asimismo, ella implicaría necesariamente la experimentación con embriones in vitro y la manipulación de los mismos. Además presentaría riesgos inevitables a causa de mutaciones o alteraciones en la regulación de la expresión genética. Por añadidura, haría obligatorio el cribado (screening) de embriones previo a la implantación, lo que tarde o temprano derivaría en prácticas propias de los partidarios del mejoramiento genético (eugenesia). Sin embargo, existe una aplicación de la ingeniería genética en seres humanos que está orientada a las células somáticas y no a las células de la línea germinal, por lo que el nuevo rasgo no se transmite a los descendientes. Se la denomina terapia génica, y consiste en la inserción de un gen foráneo en los tejidos del paciente para tratar una enfermedad. Pese a que la terapia génica humana no está exenta de connotaciones bioéticas, ellas pueden ser abordadas aplicando criterios similares a los empleados para analizar las terapias tradicionales. Hoy en día hay cerca de 1.300 pacientes registrados en todo el mundo con diagnóstico de cáncer, de una enfermedad monogénica, u de otro tipo de afección, que están recibiendo terapia génica. Es de esperar que este nuevo método para tratar enfermedades tenga éxito y se generalice en todo el planeta.

El método de diagnóstico genético preimplantatorio mencionado en el párrafo anterior merece ser analizado con mayor detalle, pues guarda semejanza con el sistema de control de calidad aplicado a la reproducción humana. Antes del advenimiento de la fertilización in vitro, las mutaciones genéticas podrían ser diagnosticadas durante el embarazo tomando muestras de tejido placentario o de líquido amniótico. En cualquiera de ambos casos, las células fetales eran analizadas para detectar la presencia de aberraciones cromosómicas o genéticas. Si se descubría que el feto estaba afectado por alguna enfermedad genética, la opción más común era el aborto, a fin de evitar el nacimiento de un bebé con anomalías. Al desarrollarse las técnicas de fertilización in vitro, fue posible cribar células embrionarias antes de ser implantadas en el útero. Este procedimiento puede llevarse a cabo con una o dos células (blastómeras) extraídas con una micropipeta desde un embrión en estadio octocelular. El embrión de mamífero puede 
reemplazar fácilmente estas células y se presume que su extracción no representa ninguna amenaza para el normal desarrollo de aquél. Se selecciona a los embriones presuntamente normales para implantarlos en el útero, mientras que los embriones presuntamente defectuosos son descartados. Tal parece que para la mayoría de las personas este procedimiento no merece ningún reparo ético.

Se estima que cada año se seleccionan 1.000 embriones mediante el diagnóstico preimplantatorio ${ }^{20}$. Fuera de que la eliminación de embriones refleja una absoluta falta de respeto por la vida humana, aún falta mucho para llegar a demostrar los beneficios de este procedimiento. Si bien algunos sostienen que el cribado de embriones ha provocado una disminución en el porcentaje de mujeres que sufren abortos, otros cuestionan los datos que respaldan esta evidencia. La controversia puede originarse en el hecho de que los investigadores han descubierto que cerca de la mitad de los embriones humanos producidos in vitro se componen de una mezcla de células normales y anormales (mosaiquismo). Estudios recientes han demostrado que estos embriones tienden a autocorregirse, eliminando espontáneamente las células afectadas por aberraciones genéticas. Lo anterior indicaría que, contrariamente a lo que se piensa, los embriones que están siendo desechados por su propensión a enfermedades genéticas podrían llegar a desarrollarse en condiciones normales. Pero aún existe otra aprensión respecto del diagnóstico preimplantatorio, en cuanto a si de verdad constituye una práctica segura para el embrión en desarrollo. El actual paradigma establece que todas las células de embriones en etapas de desarrollo muy tempranas son equivalentes y que por tanto no importaría cuál de ellas fuera extraída. Aun así, algunos investigadores han demostrado que ciertas células están predispuestas a contribuir de manera específica a la formación de futuros tejidos. Lamentablemente, es probable que se requieran varios años para determinar las verdaderas repercusiones de este drástico procedimiento en el desarrollo humano.

\section{Observaciones finales}

Por poderosa que pueda parecer, la BT no debe ser considerada una panacea que permitirá curar todas las enfermedades que nos aquejan. La BT constituye una herramienta eficaz que ofrece opciones innovadoras, las cuales reportan beneficios a prácticamente todas las áreas aplicadas: la sa-

${ }^{20}$ Goldman, B.: “The First Cut”, 2007, pp. 479-480. 
lud de seres humanos y animales, la industria de alimentos y pienso, la agricultura, el sector forestal y minero, etc. También ofrece la posibilidad de crear nuevas fuentes de energía, junto con métodos novedosos para la explotación de recursos naturales y el tratamiento de sustancias contaminantes. Con todo, la conveniencia de una determinada aplicación debe ser analizada juzgando sus méritos, situándola en su contexto bioético y político, y comparándola con otras opciones. La agricultura ofrece un ejemplo apropiado para ilustrar este criterio. En algunos casos, la plantación de un cultivo modificado genéticamente puede ser la alternativa correcta. En muchos otros, sin embargo, la agricultura tradicional seguirá siendo la mejor opción. Por otra parte, será el mercado el que finalmente determine si habrá también un lugar para la agricultura orgánica.

El rápido desarrollo de la BT moderna ha abierto escenarios anteriormente imprevistos. Hoy afrontamos situaciones que apelan a nuestro sentido bioético y que nos obligan a actuar con responsabilidad. Es necesario educar a la gente y modificar la percepción pública respecto de la BT, para así refrenar la agresividad de sus detractores, que en muchos casos han recurrido a la violencia para imponer sus puntos de vista, pero que paradójicamente suelen apoyar la destrucción de embriones humanos, lo cual revela un doble estándar bioético que entorpece un diálogo objetivo. Es requisito fundamental mantener un diálogo permanente, como también implementar normativas y directrices de carácter universal. Asimismo, es preciso sostener continuamente debates éticos, políticos y filosóficos sobre las capacidades potenciales y las consecuencias de la biotecnología, a fin de disipar los recelos que inspira la legislación vigente, la cual a veces da la impresión de adoptar medidas correctivas cuando ya es demasiado tarde.

Si bien en la mayoría de los casos es atribuible a avances realizados en naciones industrializadas, la disminución en el costo de alimentos y productos farmacéuticos podría repercutir significativamente en la realidad de los países en desarrollo. Sin embargo, el hecho de que éstos también adopten políticas destinadas a lograr la autonomía en la aplicación de las biotecnologías, consiguiendo así que su propio progreso sea sustentable, adquiere importancia estratégica. Estas políticas deberían contemplar el respaldo a programas de investigación y la formación de asociaciones internacionales en los sectores público y privado. Ahora y en el futuro, el objetivo general consiste en lograr que los procesos biotecnológicos sean más rentables y favorables al medio ambiente que los métodos tradicionales. 


\section{REFERENCIAS}

Anderson, K., L. A. Jackson, C. Pohl Nielsen: "Genetically Modified Rice Adoption: Implications for Welfare and Poverty Alleviation”. Centre for International Economic Studies. Documento de análisis 0413, 2004.

Angenent, L. T.: "Energy Biotechnology: Beyond the General Lignocellulose-to-Ethanol Pathway”. En Current Opinion in Biotechnology, 18 (2007).

Brookes, G. y P. Barfoot: "GM Crops: The First Ten Years-Global Socio-Economic and Environmental Impacts”. PG Economics, 2006.

Fairless, D.: "The Little Shrub that Could-Maybe”. En Nature, 449 (2007).

Fargione, J., J. Hill, D. Tilman, S. Polasky y P. Hawthorne: "Land Clearing and the Biofuel Carbon Debt”. En Science, 319 (2008).

Goldman, B.: "The First Cut". En Nature, 445 (2007).

International Life Sciences Institute: "Nutritional and Safety Assessments of Foods and Feeds Nutritionally Improved through BT: Case Studies”. Resumen ejecutivo del informe de una fuerza de tarea del International Life Sciences Institute, Washington, DC. Doi: 101111/j.1750-3841.2007.00579.x.

Juan Pablo II: Discursos a los miembros de la Academia Pontificia de Ciencias, 10 de noviembre de 2003.

Lawrence, S.: "State of the Biotech Sector, 2006”. En Nature Biotechnology, 25 (2007).

Mayer, J. E.: “Golden Rice, Golden Crops, Golden Prospects”. En Revista Colombiana de Biotecnología, IX (2007).

Nature Biotechnology, No 24, 2006, Editorial.

Raney, T. y P. Pingali: “Sowing a Gene Revolution”. En Scientific American, Sept. 2007.

Raney, T.: "Economic Impact of Transgenic Crops in Developing Countries”. En Current Opinion in Biotechnology, 17 (2006).

Righelato, R. y D. V. Spracklen: "Carbon Mitigation by Biofuels or by Saving and Restoring Forests?”. En Science, 317 (2007).

Searchinger, T., R. Heimlich, R. A. Houghton, F. Dong, A. Elobeid, J. Fabiosa, S. Tokgoz, D. Hayes y T-H. Yu: "Use of U.S. Croplands for Biofuels Increases Greenhouse Gases through Emissions from Land Use Change”. En Science 319 (2008).

Takahashi, K., K. Tanabe, M. Ohniki, M. Narita, T. Ichisaka, K. Tomoda y S. Yamanaka: "Induction of Pluripotent Stem Cells from Adult Human Fibroblasts by Defined Factors”. En Cell, 131 (2007).

www.isaaa.org. www.the-infoshop.com/study/fd31270-enzymes.html.

Yu, J., M. A. Vodyanik, K. Smuga-Otto, J. Antosiewicz-Bourget, J. L. Frane, S. Tian, J. Nie, G. A. Jonsdottir, V. Ruotti, R. Stewart, II. Slukvin, J. A. Thomson: "Induced Pluripotent Stem Cell Lines Derived from Human Somatic Cells”. En Science, 318 (2007). 